\title{
Ineffective esophageal motility and the vagus: current challenges and future prospects
}

This article was published in the following Dove Press journal:

Clinical and Experimental Gastroenterology

20 September 2016

Number of times this article has been viewed

\section{Ji-Hong Chen ${ }^{1,2}$}

'Department of Gastroenterology, Renmin Hospital, Wuhan University, Wuhan, People's Republic of China; 2Division of Gastroenterology, Department of Medicine, Farncombe Family Digestive Health Research Institute, McMaster University, Hamilton, ON, Canada
Correspondence: Ji-Hong Chen

Department of Gastroenterology, Health Sciences Centre, McMaster University, 3V48, 1280 Main Street West, Hamilton, ON L8S 4KI, Canada

Email jihong.chen@medportal.ca
Abstract: Ineffective esophageal motility (IEM) is characterized by low to very low amplitude propulsive contractions in the distal esophagus, hence primarily affecting the smooth muscle part of the esophagus. IEM is often found in patients with dysphagia or heartburn and is commonly associated with gastroesophageal reflux disease. IEM is assumed to be associated with ineffective bolus transport; however, this can be verified using impedance measurements or evaluation of a barium coated marshmallow swallow. Furthermore, water swallows may not assess accurately the motor capabilities of the esophagus, since contraction amplitude is strongly determined by the size and consistency of the bolus. The "peristaltic reserve" of the esophagus can be evaluated by multiple rapid swallows that, after a period of diglutative inhibition, normally give a powerful peristaltic contraction suggestive of the integrity of neural orchestration and smooth muscle action. The amplitude of contraction is determined by a balance between intrinsic excitatory cholinergic, inhibitory nitrergic, as well as postinhibition rebound excitatory output to the musculature. This is strongly influenced by vagal efferent motor neurons and this in turn is influenced by vagal afferent neurons that send bolus information to the solitary nucleus where programmed activation of the vagal motor neurons to the smooth muscle esophagus is initiated. Solitary nucleus activity is influenced by sensory activity from a large number of organs and various areas of the brain, including the hypothalamus and the cerebral cortex. This allows interaction between swallowing activities and respiratory and cardiac activities and allows the influence of acute and chronic emotional states on swallowing behavior. Interstitial cells of Cajal are part of the sensory units of vagal afferents, the intramuscular arrays, and they provide pacemaker activity to the musculature that can generate peristalsis in the absence of innervation. This indicates that a low-amplitude esophageal contraction, observed as IEM, can be caused by a multitude of factors, and therefore many pathways can be potentially explored to restore normal esophageal peristalsis.

Keywords: swallowing, achalasia, parasympathetic innervation, solitary nucleus, nucleus tractus solitarius, high-resolution manometry, interstitial cells of Cajal, gastroesophageal reflux disease

\section{Introduction}

\section{Definition}

Ineffective esophageal motility (IEM) is characterized by a distal esophageal contraction amplitude of $<30 \mathrm{mmHg}$ on conventional manometry, ${ }^{1}$ a distal contractile integral (DCI) of $<450 \mathrm{mmHg} / \mathrm{s} / \mathrm{cm}$ on high-resolution manometry (HRM) (weak contraction), or $<100 \mathrm{mmHg} / \mathrm{s} / \mathrm{cm}$ (failed contraction) in $50 \%$ or more test swallows, ${ }^{2}$ hence affecting the smooth muscle esophagus. IEM is the most common abnormality observed in routine esophageal manometry, with an estimated prevalence of $20 \%-30 \%{ }^{3}$. Scheerens et $\mathrm{al}^{4}$ reported a prevalence of $51 \%$ in patients with esophageal dysphagia. Before 2008 , 
a threshold of $30 \%$ was used, but a threshold of $50 \%$ correlates better with dysphagia and heartburn. ${ }^{1,4,5}$ IEM is manifested as a primary motor dysfunction in $50 \%$ of patients with gastroesophageal reflux disease (GERD), ${ }^{6}$ and is very common in patients with both GERD and respiratory symptoms. ${ }^{5}$ Gross pathologic injury is not necessary for motor dysfunction. ${ }^{6}$

Other conditions in which IEM is encountered are Barrett's esophagus, diabetes with neuropathy, amyloidosis, acute ethanol ingestion, chronic alcoholism with neuropathy, adenocarcinoma, eosinophilic esophagitis, endoscopic submucosal dissection, odynophagia, regurgitation, chronic cough, chest pain, and rheumatic disease. ${ }^{1,5}$

This review focuses on the mechanisms behind the potential "ineffectiveness" in IEM, with a focus on the contributions of the vagus and interstitial cells of Cajal (ICC).

\section{What is needed to confirm the "ineffective" in IEM?}

\section{Bolus transit}

The first indication of IEM comes from manometry when the amplitude of the propagating contraction is low as indicated earlier. However, this motor pattern, although classified as "ineffective", does not necessarily indicate that a bolus does not get moved through the esophagus.

Nguyen et $\mathrm{al}^{7}$ showed that the proportion of liquid boluses cleared was directly related to contraction amplitude and did not increase significantly above a threshold of $22 \mathrm{mmHg}$ in the midesophagus and $30 \mathrm{mmHg}$ in the distal esophagus. The relationship between contraction amplitude and bolus clearance appeared to be confirmed by a study in patients with severe IEM, which showed that oral bethanechol improves contraction pressures and bolus transit in the smooth muscle part of the esophagus. ${ }^{8}$ This suggests that in IEM, the amount of acetylcholine that is released from the cholinergic nerves may not be enough to give full amplitude contractions, but if it is helped by a sustained dose of the muscarinic agonist bethanechol, effective contraction amplitudes can be restored and bolus transit improved. However, in a study of 70 patients with classical manometry profiles of IEM, $48 \%$ of ineffective liquid and $38 \%$ of ineffective viscous swallows showed complete bolus transit based on impedance measurements, ${ }^{8}$ whereas $95 \%$ of manometric normal swallows of patients with normal esophageal manometry or isolated lower esophageal sphincter (LES) abnormalities (ie, hypertensive, hypotensive, and poorly relaxing LES) had normal bolus transit for liquid. Addition of impedance monitoring to manometry may allow discrimination between patients suffering from impaired bolus clearance and patients with disordered esophageal perception. ${ }^{3} \mathrm{~A}$ barium swallowing test with a marshmallow can also be used to clarify a potential relationship between impaired bolus transit and symptoms associated with dysphasia. Ineffective bolus transit cannot be determined by manometry alone.

\section{High-resolution manometry}

HRM shows that esophageal peristalsis is not a seamless wave of propagation but a coordinated sequence of contractions involving distinct segments with morphological and functional differences. ${ }^{9}$ A normal swallow-induced peristalsis includes the coordination of the following: the upper esophageal sphincter and its surrounding muscle activities, sequential contractions of the esophageal body, and the LES and crural diaphragm activities. HRM shows whether or not the propulsive contraction reaches the LES, which may affect bolus transit. HRM can also identify high intrabolus pressure, which may impair peristalsis. HRM according to the Chicago classification v 3.0 identifies weak and failed peristalsis as described earlier and considers both ineffective. IEM in conjunction with transient lower esophageal sphincter relaxation (TLESR), with or without esophageal shortening, hiatal hernia, hypotensive upper esophageal sphincter or hypotensive LES, may suggest different underlying pathophysiologies. The nature of the contraction following multiple rapid swallows (MRS) will help to confirm the peristaltic reserve. Responses to solid food may reproduce typical symptoms. Testing responses to prokinetics may provide evidence for clinical management. Although all these parameters characterize esophageal peristalsis, they may not necessarily predict GERD. ${ }^{10}$ If antireflux surgical intervention is contemplated, it was suggested that the higher the DCI ratio, the lower the likelihood of postsurgery dysphagia. ${ }^{2}$ Antireflux surgery may alleviate IEM or IEM may appear after surgery. ${ }^{11}$

\section{Water versus viscous swallows and bolus size}

Decisions about ineffective motility have to take into account that contraction amplitudes required to empty a bolus vary with the consistency of the bolus. ${ }^{8}$ It has been reported that $14.3 \%$ of patients with abnormal transit of liquids showed normal transit of a viscous bolus. ${ }^{8}$ Hence, a challenge with only liquid swallows may not be enough to identify clinically relevant IEM. Secondary peristalsis is more often disturbed compared with primary peristalsis. ${ }^{12}$ With spontaneous secondary peristalsis, the contraction amplitude might depend to a large extent on the bolus size; measurement of force of contraction in response to balloon distention can accurately measure sensory dysfunction. ${ }^{12}$ 


\section{Incorporation of a meal in standard manometry}

Sweis et $a l^{13}$ proposed the inclusion of a standard meal in motility testing. They found that spontaneous reporting of symptoms did not occur during water swallows but $67 \%$ of patients reported symptoms during a meal and $75 \%$ of these symptoms were related to an observed motor dysfunction. Often, a motor dysfunction was associated with reflux or regurgitation following a meal. Importantly, bolus retention was most often associated with four or five ineffective swallows in sequence rather than a single "ineffective" motor pattern. ${ }^{13}$ HRM during a meal can also identify behavioral abnormalities such as rumination. ${ }^{13}$

\section{Multiple rapid swallows}

Performing a MRS test to assess the "peristaltic reserve" has been advocated as an adjunct to standard high- or lowresolution manometry. ${ }^{14}$ MRS consists of administering five $2 \mathrm{~mL}$ water swallows separated by 2 - to 3 -second intervals; MRS profoundly inhibits the esophageal body and LES, not allowing significant peristaltic propagation but is normally followed by an esophageal contraction of increased amplitude. With HRM, the contraction that followed MRS is compared with the average $\mathrm{DCI}^{2}$ of the prior ten test swallows giving a DCI ratio. A DCI ratio of $>1$ is present in $78 \%$ of healthy individuals. Whether assessing the DCI ratio is useful was questioned recently and it was advocated that one should simply use low- or high-amplitude contractions with $<450 \mathrm{mmHg} / \mathrm{s} / \mathrm{cm}$ as a benchmark for ineffective motility. ${ }^{15}$ It is likely that manometry with additional MRS can better assess a clinically relevant motor dysfunction, better predict ineffective bolus transit, and can better predict success of treatments..$^{15}$ A strong performance with MRS in patients with IEM suggests "peristaltic reserve" and may predict success of prokinetic treatment. A poor contraction with MRS in patients with dysphagia showing normal swallowinduced peristalsis suggests some diminished mechanism of cholinergic excitation. ${ }^{14}$ Almost $70 \%$ of 109 patients with esophageal symptoms and normal manometry had abnormal MRS, mainly consisting of an inability to increase the amplitude of distal esophageal body contractions after MRS. A total of $38 \%$ of 48 patients with IEM were able to generate normal contractions after MRS. ${ }^{14}$

\section{The role of LES relaxation in IEM}

Weak peristalsis is accompanied by low-amplitude contractions and most often also by short-duration LES relaxation; the duration of LES relaxation appears to play a role in disordered bolus transit and clearance in dysphagia patients with normal esophageal manometry and with IEM. ${ }^{3}$ Mean duration of LES relaxation for viscous swallows with normal bolus transit was longer than that of swallows with abnormal bolus transit probably related to the fact that the duration of LES relaxation is modified by the timing of the postrelaxation LES contraction. ${ }^{3}$ The role of LES relaxation is probably of less importance for bolus transit compared with esophageal peristalsis. $^{8}$

\section{Vagal control of esophageal peristalsis}

The amplitude of swallow- and bolus-induced peristaltic contractions is determined by the balance of inhibitory and excitatory neural activities coming from the autonomic and intrinsic nervous systems (Figure 1). ${ }^{16}$

At rest, the esophagus is quiet and a stimulus is required to generate motility. A bolus in the oropharyngeal region activates the swallowing center in the brain that initiates sequential vagally mediated contractions in the striated and the smooth muscle esophagus (Figure 2). A swallowed bolus triggers many sensory factors giving vagal input to the solitary nucleus that evokes peristalsis via vagal dorsal motor neurons to the smooth muscle part. The nucleus ambiguous houses the pattern generator for the striated esophagus. The bolus to be swallowed has to have minimal features; otherwise, the sensory coding produces an uncertain evaluation by the solitary nucleus and an inefficient swallow may result. ${ }^{17,18}$ An occasionally failed swallow-induced esophageal peristalsis in all or part of the esophagus is common in humans, in particular, with dry swallows.

The bolus-evoked peristaltic activity in the smooth muscle esophagus consists of a wave of inhibition (deglutitive inhibition, including LES relaxation ${ }^{19}$ ) followed by a wave of contraction; the efferent output shows first the release of nitric oxide to inhibit the musculature, and thereafter a cholinergically mediated contraction occurs with a variable delay, the longest delay in the distal esophagus. The delay appears to be generated in part by continuing bolus-induced activation of intramural descending nitrergic nerves with long projections. ${ }^{18}$

Bolus-induced, secondary peristalsis can be initiated by intrinsic neural programs independent of vagal activity, but is influenced by vagal activity. ${ }^{20}$ Normal swallowing is likely a combination of vagal and intrinsic activity. ${ }^{18}$

The musculature itself, including the ICC pacemaker cells, can provide rhythmicity to esophageal smooth muscle; 


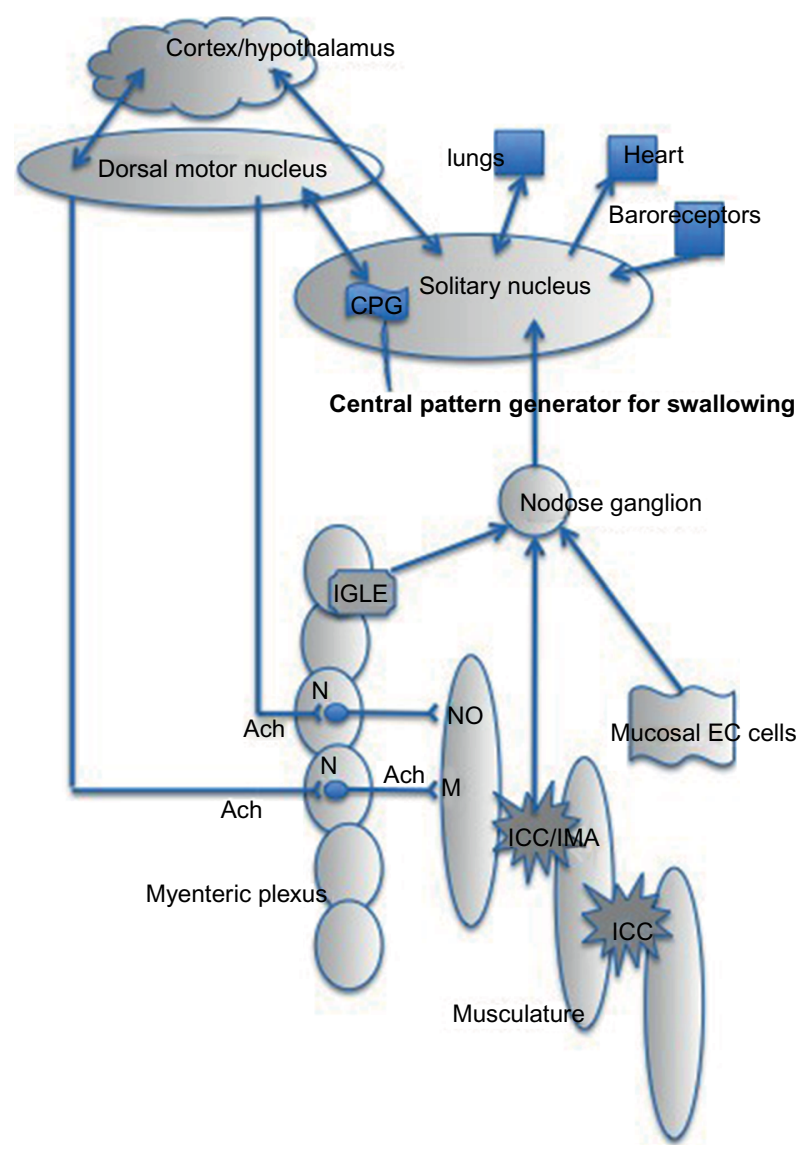

Figure I Vagal innervation of the smooth muscle esophagus.

Notes: The solitary nucleus (or nucleus of the solitary tract) receives sensory input from a wide variety of organs and houses the central pattern generator for the smooth muscle part of the esophagus. The nodose ganglion is a gateway for sensory neurons to the solitary nucleus. It contains the cell bodies of the afferent nerves from the esophagus. The intramuscular arrays are vagal afferent nerve endings that mingle with ICC-IM in the musculature to form sensory units. The intramuscular ICC are likely the pacemaker cells of the esophagus that can generate rhythmic propulsive activity in the absence of innervation. The IGLEs are the vagal afferent nerve endings in the myenteric plexus. EC cells secrete 5-HT upon stimulation that activates vagal sensory neurons. The dorsal motor nucleus of the vagus sends motor neurons to the esophageal body, after receiving central pattern generator information from the solitary nucleus. The cortex/hypothalamus communicates with the solitary nucleus, so that ones acute or chronic emotional state can influence any aspect of swallowing. Abbreviations: 5-HT, 5-hydroxytryptamine, Ach, the neurotransmitter acetylcholine; CPR, central pattern generator; EC, enterochromaffin cells; ICC, interstitial cells of Cajal; IGLEs, intraganglionic laminar endings; IMA, intramuscular array; ICC-IM, intramuscular ICC; M, muscarinic receptor; $\mathrm{N}$, nicotinic synapse; $\mathrm{NO}$, nitric oxide.

in vitro, without innervation, cholinergic stimulation produces peristaltic rhythmic contractions at a velocity similar to that of swallow-induced peristalsis, ${ }^{21}$ but how this is integrated in the neural networks during swallow- or bolusinduced peristalsis is not known. ${ }^{18}$ Only intramuscular ICC form a dense network in the esophagus. ${ }^{22-24}$ The rhythmic contractions likely associated with ICC pacemaker activity become obvious in some patients with achalasia when strong rhythmic nonpropagating simultaneous pressure waves are present; the hypothesis is that normal nitrergic inhibition of the pacemaker activity is lost in achalasia. ${ }^{23-25}$ In the small intestine and colon, the ICC produce electrical slow waves that propagate based on a frequency gradient that gives direction to peristalsis. ${ }^{26-28}$ This may be similar in the esophagus where regular slow-wave activity at four to seven cycles per minute has been recorded in healthy volunteers, propagating at $4-6 \mathrm{~cm} / \mathrm{s}^{29}$ The close association between nitrergic nerves and intramuscular ICC would suggest that they may become reduced simultaneously in achalasia; however, this was not observed; in patients with severe reduction of nitrergic nerves, ICC could be structurally normal. ${ }^{23}$ This appeared to confirm that nitrergic nerves are primarily responsible for the propagating nature of the esophageal contraction. It is interesting to note that the frequency of the contractions in an achalasia patient occurred at seven cycles per minute, ${ }^{24}$ in the range of the slow-wave activity. ${ }^{29}$ It was proposed that weak peristalsis or reflux may be due to failure of ICC to produce significant slow-wave activity. ${ }^{29}$

\section{The vagal sensory pathways from the smooth muscle esophagus}

Vagal afferent neurons originate in special terminal structures in the myenteric plexus ganglia, the intraganglionic laminar endings (IGLEs), ${ }^{30}$ sensing shearing and tension, ${ }^{31}$ or within the musculature in intramuscular arrays (IMAs) ${ }^{32}$ where the nerve endings interact with intramuscular ICC (ICC-IM) but not with ICC associated with the myenteric plexus. ${ }^{33}$ The ICC-IM form a three-dimensional network within the circular muscle layer of the esophagus coursing parallel to smooth muscle fibers; ${ }^{22}$ they form gap junctions and peg and socket contacts with smooth muscle cells and are therefore ideally suited as stretch receptors. ${ }^{3434,35}$ It is the ideal configuration to facilitate bidirectional communication between the vagus nerve and smooth muscle cells. ${ }^{33}$ ICC-IM are also heavily innervated by nitrergic nerves; it is not known how innervation of ICC affects vagal sensory information. Through IGLEs and IMAs a bolus transmits sensory information to the solitary nucleus via the nodose ganglion to regulate the intensity and timing of vagal output via vagal dorsal motor neurons that determines the timing and amplitude of the peristaltic contractions. ${ }^{18}$ Larger boluses and greater viscosity increase the contraction amplitude and duration and slow peristaltic velocity. IEM associated with secondary distention-induced peristalsis may therefore be caused by disturbance of sensory vagal pathways affecting motor function. In addition to sensory nerve endings located within the musculature, mucosal vagal afferents convey low threshold 


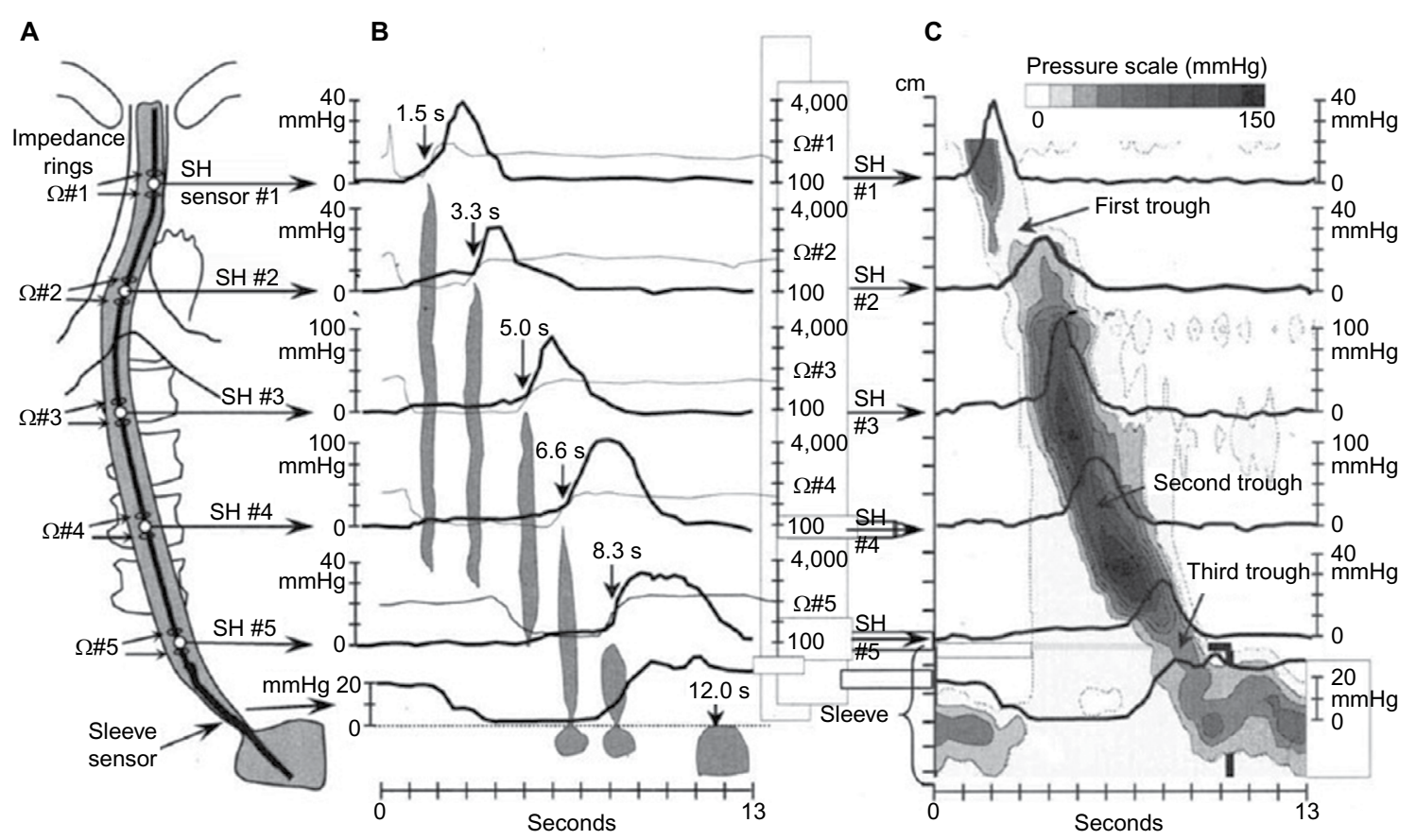

Figure 2 Illustration of the relationship between videofluoroscopic, manometric, impedance, and topographic representations of esophageal peristalsis.

Notes: (A) Schematic drawing of placement of a combined manometry/intraluminal impedance monitoring system with five manometric side holes (SHs) spaced $4 \mathrm{~cm}$ apart and a $6 \mathrm{~cm}$ sleeve sensor placed just distal to the last manometric port. (B) Concurrent videofluoroscopic, manometric, and multichannel intraluminal impedance recordings of a $5 \mathrm{~mL}$ Renografin swallow that was completely cleared by one peristaltic sequence. (C) Comparison of conventional manometry obtained with a sleeve assembly as depicted in (A) and high-fidelity manometry with recording sites at I cm intervals displayed topographically as an isocontour plot. The standard manometric recordings are superimposed on the isocontour plot at axial locations corresponding to the equivalent portion of the high-fidelity manometry it represents. Reprinted from Gastroenterology. Vol I28(I). Pandolfino JE, Kahrilas PJ, American GA.AGA technical review on the clinical use of esophageal manometry. Pages:209-224. Copyright 2005, with permission from Elsevier. ${ }^{77}$

functional information to the brain, including mechanical, chemical, and temperature changes. ${ }^{36}$ This information may come directly from free nerve endings at the base of epithelial cells or indirectly via enterochromaffin cells or mast cells. ${ }^{36}$

\section{The vagal motor pathways to the smooth muscle esophagus}

The sensory information that is processed in the solitary nucleus and the reticular formations around the solitary nucleus is transmitted to the dorsal motor nucleus. ${ }^{17}$ The rostral neurons in the dorsal motor nucleus of the vagus nerve preferentially innervate the excitatory motor neurons, whereas the neurons in the caudal region innervate inhibitory motor neurons. ${ }^{37,38}$ Through extensive branching, via nicotinic synapses, vagal efferents communicate extensively within the myenteric plexus ganglia and stimulate via nicotinic synapses to cholinergic as well as nitrergic neurons to affect smooth muscle cells (Figure 1). Possibly $60 \%-70 \%$ of myenteric neurons are connected to vagal cholinergic efferent neurons. ${ }^{36}$ Excitatory cholinergic motor neurons must be adequately stimulated by central and/or peripheral neural input to obtain a sufficient amplitude of peristaltic contractions. Ultimately, the threshold for peristaltic contraction, its timing in the peristaltic sequence, and the contraction amplitude are determined by a balance between excitatory and inhibitory influences at the muscle level, ${ }^{18}$ as described earlier.

\section{Vagal efferent pathways to the esophagus via the stomach}

In patients with acid reflux, spontaneous TLESRs, occurring primarily by gastric distention, are accompanied by strong inhibition of esophageal body smooth muscle as evidenced by incomplete swallow-induced peristalsis during this activity. ${ }^{39}$ Careful analysis of TLESRs lasting $>15$ seconds, which were not influenced by other events, showed that $91 \%$ of the swallows during these long TLESRs were accompanied by peristaltic waves that were only seen in the most proximal lead. ${ }^{39}$ Poor peristaltic activity during TLESR was not observed in healthy persons. ${ }^{40}$ This indicates that IEM may be associated with abnormal vagal tone derived from abnormal sensory and/or motor vagal pathways from the stomach via the solitary nucleus to the esophagus. GERD is treated with antacids, but acid secretion is not the problem; the cause is a disordered control of the gastroesophageal reflux barrier. ${ }^{12}$ This suggests that the vagal mechanoreceptors may be the most important cellular target for future pharmacological treatment. ${ }^{12}$ The mechanoreceptors include the IGLEs and the IMAs. ${ }^{32}$ TLESRs accompanied by some form of reflux 
are markedly increased after a meal, coinciding with a change in vagal activity as measured by vagal input to the cardiovascular system. ${ }^{41}$ Gastric vagal afferents send powerful vagal inhibition to the LES and esophagus, likely in part by suppressing vagal excitatory input ${ }^{12}$ that might be measured as reduced vagal cardiac tone. Hence, vagal tone, regulated by the central nervous system (CNS) and modified by vagal afferents, and receptors on the cell types that constitute vagal mechanosensors, including ICC, may be important targets for GERD treatment. ${ }^{36}$ Abnormal vagal activity was also suggested to be involved in IEM commonly observed in asthmatics. ${ }^{42}$

\section{Many CNS activities can influence swallowing via the solitary nucleus}

The fascinating feature of the solitary nucleus is that it receives sensory information from the gut, the lung, the heart, and the vasculature and sends this information to the motor neurons that control these organs. Although input from different organs has a relation to specific subnuclei, this organ-specific distribution is not mutually exclusive, and visceral afferents have been shown to distribute widely within other subnuclei of the solitary nucleus. ${ }^{31,43}$ Dye labeling of swallow-related neurons showed many collaterals that presumably contact other neurons within the solitary nucleus. ${ }^{44}$ During a swallow, intracellular recording of respiration-modulated neurons in the solitary nucleus shows bursts of action potentials. ${ }^{44}$ This interaction at the level of the solitary nucleus is likely a reason why diseases with a high risk of aspiration have neural incoordination of breathing and swallowing. ${ }^{44}$ The solitary nucleus also houses the dorsal respiratory group involved in the generation of respiratory rhythm. ${ }^{44}$ The solitary nucleus is the primary site for reception of vagal afferents stimulated by baroreceptors. ${ }^{45}$ The solitary nucleus projects vagal efferents to the sinus node to affect heart rate, it also projects to spinal sympathetic neurons to increase heart rate and affect blood pressure. ${ }^{46}$ The interactions between various branches of the vagal nerve is demonstrated by a change in heart rate when a balloon is distended in the esophagus. Tougas et $\mathrm{al}^{47}$ showed that stimulation of the distal esophagus by balloon distension induced cardiac autonomic changes such as an decrease in heart rate, an increase in vagal activity measured by the highfrequency component of heart rate variability, and a reduction in sympathetic activity measured by its low-frequency component, demonstrating the link between esophageal sensory pathways and cardiac autonomic nervous system function.

Communication between gut microbiota and the brain involves vagal sensory pathways. ${ }^{46}$ Chronic probiotic treatment can alter $\gamma$-aminobutyric acid expression in the cortex, which is dependent on vagal activity, and this information projects to the solitary nucleus where it can affect vagal output to the esophagus..$^{48}$ Bifidobacterium longum has anxiolytic effects that require intact vagal pathways and act through changes in enteric neural excitability. ${ }^{49,50}$ Bacterial infections in the gut or abnormal gut microbiota can lead to anxiety behavior; the gut signals are carried by the vagus to the cortex and hypothalamus that project to the solitary nucleus. ${ }^{51-54}$ The descending excitatory and inhibitory drives from the cortex and subcortex can influence the oropharyngeal initiation of swallowing and modulate the central patterns generator for swallowing. ${ }^{55}$ The cortex is plastic and neural circuitry can be influenced by trauma that may have long-lasting effects. ${ }^{56}$ This can influence cortex information that is communicated to the solitary nucleus, which can affect cardiac function ${ }^{56}$ and likely esophageal function.

Neural pathways that link the cortex, the hypothalamus, and the central amygdala to the solitary nucleus suggest that neural activity in various brain centers will influence solitary nucleus output. ${ }^{36,57,58}$ A psychiatric disorder such as major depression that affects the cortex may affect the output of the solitary nucleus thereby giving gastrointestinal (GI) symptoms. ${ }^{59,60}$ This may be the reason that treatment of depression can alleviate GI symptoms. Drugs that work on the brain in psychiatric disorders such as olanzapine also work on $5-\mathrm{HT}_{2 \mathrm{~A}}$ receptors that are found in many areas of the brain including the solitary nucleus and it might be the reason that it can help alleviate psychiatric as well as GI symptoms. ${ }^{59}$ For a subset of patients, anxiety and emotion may be a direct cause of esophageal dysfunction. ${ }^{61}$

The solitary nucleus also houses the central pattern generator for vomiting. Chemosensitive receptors detect emetic agents in the blood and relay this information by means of neurons in the area postrema to the adjacent solitary nucleus from which projections are made to the central pattern generator for vomiting. ${ }^{62}$

\section{Therapeutic interventions in IEM}

Weak peristalsis accompanied by low-amplitude contractions and short-duration LES relaxation ${ }^{63}$ can be related to abnormal control of peristaltic activity at the level of the CNS, the enteric nervous system, or the muscle layers including the ICC pacemaker cells and treatment, therefore, may involve any or all of the control systems. Antireflux medication may inhibit acid reflux but it may not improve esophageal motor function. ${ }^{6}$

The critical role of the vagus in the control of esophageal peristalsis makes it logical to assume that pharmacological 
treatment of vagal dysfunction may be one of the avenues to treat IEM. Vagal activity can potentially be modulated by the numerous receptors on its sensory and motor neurons, extensively reviewed elsewhere. ${ }^{12,46,64,65}$ Buspirone has been shown to increase LES pressure and amplitude of esophageal contractions possibly associated with $5-\mathrm{HT}_{1 \mathrm{~A}}$ receptors stimulating acetylcholine release in the hippocampus. ${ }^{4,66} 5-\mathrm{HT}_{3}$ receptors are potential targets present on vagal afferent endings in the solitary nucleus and in the nodose ganglion. ${ }^{46,67}$ Vagal afferents show spontaneous rhythmic activity that is attenuated by the $5-\mathrm{HT}_{3}$ antagonist, granisetron, and by transient receptor potential vanilloid receptor 1 antagonist, capsazepine, suggesting that tonic activation of 5- $\mathrm{HT}_{3}$ and transient receptor potential vanilloid receptor 1 contributes to the spontaneous activity. ${ }^{31}$ Patients with multiple sclerosis and severe dysphagia improved with electrical stimulation of the solitary nucleus over a 3 -month period with an implanted nerve stimulator. ${ }^{68}$ On the other hand, dysphagia can be a side effect of treatment of epilepsy with vagal nerve stimulation. The 5- $\mathrm{HT}_{4}$ agonist prucalopride decreased esophageal acid exposure but did not affect parameters of esophageal motor activity nor LES relaxation, ${ }^{69}$ although another $5-\mathrm{HT}_{4}$ agonist tegaserod (it is also a $5-\mathrm{HT}_{2 \mathrm{~B}}$ antagonist) did improve midesophageal motility, the peristaltic propagation velocity and in some patients it improved bolus transit. ${ }^{70}$

Eating habits may influence IEM since the nature and size of the bolus strongly influence the amplitude, duration, and velocity of the peristaltic wave. ${ }^{18}$ Patients may be advised to chew sufficiently to stimulate the vagal output to the esophagus. ${ }^{4}$ In some patients, regularly chewing gum appears to have a beneficial effect in IEM, ${ }^{71}$ likely through vagal activation. Chewing gum also benefits gastric motility through vagal stimulation. ${ }^{72,73}$

The problem may also lie in the musculature. In systemic sclerosis, esophageal aperistalsis and IEM are common, ${ }^{74}$ possibly related to circulating antibodies against the muscarinic M3 receptor. ${ }^{75}$ Vagal sensory units in the esophagus and fundus, associated with ICC, are major potential targets for drug development. ${ }^{12}$

Manometry may aid in predicting success of treatment for IEM. Prokinetic treatment may be encouraged in patients who show a good response to MRS, judged by successful treatment with the cholinesterase inhibitor edrophonium intravenous. ${ }^{14}$ Autonomic nerve dysfunction as judged by cardiovascular reflex tests was related to delayed transit and abnormal peristalsis, ${ }^{76}$ and monitoring vagal activity, even indirectly, may also aid in understanding pathophysiology and potentially predicting success of treatment.

\section{Conclusion}

Weak peristaltic contractions are very often observed during an esophageal motility test. To determine if this constitutes a motor pattern that is ineffective in bolus transit, a simple wet swallow manometry test is not sufficient and hence additional tools are suggested in this review. Clinically relevant IEM may well be related to some kind of vagal dysfunction or reduced vagal tone since the vagal activity is paramount in controlling all aspects of esophageal peristalsis. Since the vagal afferent neurons communicate with many parts of the brain involved in control of heart rate and respiration as well as anxiety and emotion, IEM can be caused or influenced by a variety of extragastrointestinal conditions.

\section{Acknowledgments}

The author would like to thank Professor Paul Moayyedi and Dr Frances Tse for many levels of support for my fellowship; Professor Stephen Collins and Dr Premsyl Bercik for their strong continuing support in motility training at McMaster; and Professor Jan D Huizinga for many discussions, support for literature research, and critical reading of the manuscript.

\section{Disclosure}

The author reports no conflicts of interest in this work.

\section{References}

1. Blonski W, Vela M, Safder A, Hila A, Castell DO. Revised criterion for diagnosis of ineffective esophageal motility is associated with more frequent dysphagia and greater bolus transit abnormalities. $\mathrm{Am} J$ Gastroenterol. 2008;103(3):699-704.

2. Kahrilas PJ, Bredenoord AJ, Fox M, et al; International High Resolution Manometry Working Group. The Chicago classification of esophageal motility disorders, v3.0. Neurogastroenterol Motil.2015;27(2):160-174.

3. Conchillo JM, Nguyen NQ, Samsom M, Holloway RH, Smout AJ. Multichannel intraluminal impedance monitoring in the evaluation of patients with non-obstructive Dysphagia. Am J Gastroenterol. 2005;100(12): 2624-2632.

4. Scheerens C, Tack J, Rommel N. Buspirone, a new drug for the management of patients with ineffective esophageal motility. United European Gastroenterol J. 2015;3(3):261-265.

5. Abdel Jalil AA, Castell DO. Ineffective esophageal motility (IEM): the old-new Frontier in esophagology. Curr Gastroenterol Rep. 2016; 18(1): 1 .

6. Ho SC, Chang CS, Wu CY, Chen GH. Ineffective esophageal motility is a primary motility disorder in gastroesophageal reflux disease. Dig Dis Sci. 2002;47(3):652-656.

7. Nguyen NQ, Tippett M, Smout AJ, Holloway RH. Relationship between pressure wave amplitude and esophageal bolus clearance assessed by combined manometry and multichannel intraluminal impedance measurement. Am J Gastroenterol. 2006;101(11):2476-2484.

8. Tutuian R, Castell DO. Clarification of the esophageal function defect in patients with manometric ineffective esophageal motility: studies using combined impedance-manometry. Clin Gastroenterol Hepatol. 2004;2(3):230-236.

9. Lin Z, Yim B, Gawron A, Imam H, Kahrilas PJ, Pandolfino JE. The four phases of esophageal bolus transit defined by high-resolution impedance manometry and fluoroscopy. Am J Physiol Gastrointest Liver Physiol. 2014;307(4):G437-G444. 
10. van Hoeij FB, Smout AJ, Bredenoord AJ. Predictive value of routine esophageal high-resolution manometry for gastro-esophageal reflux disease. Neurogastroenterol Motil. 2015;27:963-970.

11. Mello MD, Shriver AR, LiY, Patel A, Gyawali CP. Ineffective esophageal motility phenotypes following fundoplication in gastroesophageal reflux disease. Neurogastroenterol Motil. 2016;28(2):292-298.

12. Page AJ, Blackshaw LA. Roles of gastro-esophageal afferents in the mechanisms and symptoms of reflux disease. In: Canning BJ, Spina D, editors. Handbook of Experimental Pharmacology. 194 ed. Springer Verlag: Berlin, Germany; 2009:227.

13. Sweis R, Anggiansah A, Wong T, Brady G, Fox M. Assessment of esophageal dysfunction and symptoms during and after a standardized test meal: development and clinical validation of a new methodology utilizing high-resolution manometry. Neurogastroenterol Motil. 2014;26(2):215-228.

14. Fornari F, Bravi I, Penagini R, Tack J, Sifrim D. Multiple rapid swallowing: a complementary test during standard oesophageal manometry. Neurogastroenterol Motil. 2009;21:718.e41.

15. Min YW, Shin I, Son HJ, Rhee PL. Multiple rapid swallow maneuver enhances the clinical utility of high-resolution manometry in patients showing ineffective esophageal motility. Medicine (Baltimore). 2015;94(40):e1669.

16. Jean A. Brain stem control of swallowing: neuronal network and cellular mechanisms. Physiol Rev. 2001;81(2):929-969.

17. Ertekin C, Aydogdu I. Neurophysiology of swallowing. Clin Neurophysiol. 2003;114(12):2226-2244.

18. Paterson WG, Diamant NE. Esophageal motor physiology. In: Shaker REA, editor. Principles of Diglutition: A Multidisciplinary Text for Swallowing and Its Disorders. New York: Springer; 2013:303-318.

19. Reynolds RP, El-Sharkawy TY, Diamant NE. Lower esophageal sphincter function in the cat: role of central innervation assessed by transient vagal blockade. Am J Physiol. 1984;246(6 Pt 1):G666-G674.

20. Goyal RK, Paterson WG. Esophageal motility. In: Pollock DM, editor. Comprehensive Physiology. Bethesda, MD: The American Physiological Society; 2011:865-908.

21. Preiksaitis HG, Diamant NE. Myogenic mechanism for peristalsis in the cat esophagus. Am J Physiol. 1999;277(2 Pt 1):G306-G313.

22. Berezin I, Daniel EE, Huizinga JD. Ultrastructure of interstitial cells of Cajal in the canine distal esophagus. Can J Physiol Pharmacol. 1994;72(9):1049-1059.

23. Zarate N, Wang XY, Tougas G, et al. Intramuscular interstitial cells of Cajal associated with mast cells survive nitrergic nerves in achalasia. Neurogastroenterol Motil. 2006;18(7):556-568.

24. Chen JH, Wang XY, Liu LW, et al. On the origin of rhythmic contractile activity of the esophagus in early achalasia, a clinical case study. Front Neurosci. 2013;7:77.

25. Paterson WG. Esophageal and lower esophageal sphincter response to balloon distention in patients with achalasia. Dig Dis Sci. 1997;42(1):106-112.

26. Huizinga JD, Thuneberg L, Kluppel M, Malysz J, Mikkelsen HB, Bernstein A. W/kit gene required for interstitial cells of Cajal and for intestinal pacemaker activity. Nature. 1995;373(6512):347-349.

27. Huizinga JD, Thuneberg L, Vanderwinden JM, Rumessen JJ. Interstitial cells of Cajal as targets for pharmacological intervention in gastrointestinal motor disorders. Trends Pharmacol Sci. 1997;18(10):393-403.

28. Streutker CJ, Huizinga JD, Driman DK, Riddell RH. Interstitial cells of Cajal in health and disease. Part I: normal ICC structure and function with associated motility disorders. Histopathology. 2007;50(2): 176-189.

29. Shafik A, El-Sibai O, Shafik I, Shafik A. Electroesophagogram in gastroesophageal reflux disease with a new theory on the pathogenesis of its electric changes. BMC Surg. 2004;4:13.

30. Berthoud HR, Patterson LM, Neumann F, Neuhuber WL. Distribution and structure of vagal afferent intraganglionic laminar endings (IGLEs) in the rat gastrointestinal tract. Anat Embryol (Berl). 1997;195(2):183-191.

31. Beyak MJ, Bulmer DCE, Jiang W, Keating C, Rong W, Grundy D. Extrinsic sensory afferent nerves innervating the gastrointestinal tract. In: Johnson LR, editor. Physiology of the Gastrointestinal Tract. 4th ed. Academic Press. 2006:685-727.
32. Powley TL, Wang XY, Fox EA, Phillips RJ, Liu LW, Huizinga JD. Ultrastructural evidence for communication between intramuscular vagal mechanoreceptors and interstitial cells of Cajal in the rat fundus. Neurogastroenterol Motil. 2008;20(1):69-79.

33. Huizinga JD, Reed DE, Berezin I, et al. Survival dependency of intramuscular ICC on vagal afferent nerves in the cat esophagus. $\mathrm{Am} J$ Physiol Regul Integr Comp Physiol. 2008;294(2):R302-R310.

34. Powley TL, Hudson CN, McAdams JL, Baronowsky EA, Phillips RJ. Vagal intramuscular arrays: the specialized mechanoreceptor arbors that innervate the smooth muscle layers of the stomach examined in the rat. J Comp Neurol. 2016;524(4):713-737.

35. Powley TL, Baronowsky EA, Gilbert JM, et al. Vagal afferent innervation of the lower esophageal sphincter. Auton Neurosci. 2013;177(2): 129-142.

36. Tache $Y$. The parasympathetic nervous system in the pathophysiology of the gastrointestinal tract. In: Bolis CL, Licinio J, Govoni S, editors. Handbook of the Autonomic Nervous System. Basel: Marcel Dekker Inc; 2003:463-504.

37. Boeckxstaens GE. The lower oesophageal sphincter. Neurogastroenterol Motil. 2005;17(Suppl 1):13-21.

38. Martino R, Terrault N, Ezerzer F, Mikulis D, Diamant NE. Dysphagia in a patient with lateral medullary syndrome: insight into the central control of swallowing. Gastroenterology. 2001;121(2):420-426.

39. Dent J, Holloway RH, Toouli J, Dodds WJ. Mechanisms of lower oesophageal sphincter incompetence in patients with symptomatic gastrooesophageal reflux. Gut. 1988;29(8):1020-1028.

40. Sifrim D, Janssens J, Vantrappen G. Transient lower esophageal sphincter relaxations and esophageal body muscular contractile response in normal humans. Gastroenterology. 1996;110(3):659-668.

41. Kuo P, Bravi I, Marreddy U, Aziz Q, Sifrim D. Postprandial cardiac vagal tone and transient lower esophageal sphincter relaxation (TLESR). Neurogastroenterol Motil. 2013;25(10):841.e639.

42. Amarasiri DL, Pathmeswaran A, Dassanayake AS, de Silva AP, Ranasinha CD, de Silva HJ. Esophageal motility, vagal function and gastroesophageal reflux in a cohort of adult asthmatics. BMC Gastroenterol. 2012;12:140.

43. Babic T, Ambler J, Browning KN, Travagli RA. Characterization of synapses in the rat subnucleus centralis of the nucleus tractus solitarius. J Neurophysiol. 2015;113(2):466-474.

44. Bautista TG, Sun QJ, Pilowsky PM. The generation of pharyngeal phase of swallow and its coordination with breathing: interaction between the swallow and respiratory central pattern generators. Prog Brain Res. 2014;212:253-275.

45. Beyak MJ. Visceral afferents - determinants and modulation of excitability. Auton Neurosci. 2010;153(1-2):69-78.

46. Browning KN, Travagli RA. Central nervous system control of gastrointestinal motility and secretion and modulation of gastrointestinal functions. Compr Physiol. 2014;4(4):1339-1368.

47. Tougas G, Kamath M, Watteel G, et al. Modulation of neurocardiac function by oesophageal stimulation in humans. Clin Sci (Lond). 1997;92(2):167-174.

48. Bravo JA, Forsythe P, Chew MV, et al. Ingestion of Lactobacillus strain regulates emotional behavior and central GABA receptor expression in a mouse via the vagus nerve. Proc Natl Acad Sci U SA. 2011;108(38): 16050-16055.

49. Bercik P, Park AJ, Sinclair D, et al. The anxiolytic effect of Bifidobacterium longum NCC3001 involves vagal pathways for gut-brain communication. Neurogastroenterol Motil. 2011;23(12):1132-1139.

50. Khoshdel A, Verdu EF, Kunze W, McLean P, Bergonzelli G, Huizinga JD. Bifidobacterium longum NCC3001 inhibits AH neuron excitability. Neurogastroenterol Motil. 2013;25(7):e478-e484.

51. Goehler LE, Lyte M, Gaykema RP. Infection-induced viscerosensory signals from the gut enhance anxiety: implications for psychoneuroimmunology. Brain Behav Immun. 2007;21(6):721-726.

52. De Palma G, Blennerhassett P, Lu J, et al. Microbiota and host determinants of behavioural phenotype in maternally separated mice. Nat Commun. 2015;6:7735. 
53. Collins SM, Surette M, Bercik P. The interplay between the intestinal microbiota and the brain. Nat Rev Microbiol. 2012;10(11):735-742.

54. Barbara G, Cremon C, Stanghellini V. Inflammatory bowel disease and irritable bowel syndrome: similarities and differences. Curr Opin Gastroenterol. 2014;30(4):352-358.

55. Martin RE, Goodyear BG, Gati JS, Menon RS. Cerebral cortical representation of automatic and volitional swallowing in humans. $J$ Neurophysiol. 2001;85(2):938-950.

56. Cechetto DF. Cortical control of the autonomic nervous system. Exp Physiol. 2014;99(2):326-331.

57. Jean A. Le noyau du faisceau solitaire: Aspects neuroanatomiques, neurochimiques et fonctionnels [The nucleus tractus solitarius: neuroanatomic, neurochemical and functional aspects]. Arch Int Physiol Biochim Biophys. 1991;99(5):A3-A52. French.

58. Castle M, Comoli E, Loewy AD. Autonomic brainstem nuclei are linked to the hippocampus. Neuroscience. 2005;134(2):657-669.

59. Bourke J, Soldan J, Silk DB, Aziz Q, Libby GW. Idiopathic' intestinal failure - the importance of identifying and treating primary psychopathology. Neurogastroenterol Motil. 2012;24(3):242-251.

60. Schwaber JS, Kapp BS, Higgins G. The origin and extent of direct amygdala projections to the region of the dorsal motor nucleus of the vagus and the nucleus of the solitary tract. Neurosci Lett. 1980;20(1):15-20.

61. BakerLH,Lieberman D, Oehlke M. Psychological distress in patients with gastroesophageal reflux disease. Am J Gastroenterol. 1995;90(10):1797-1803.

62. Hornby PJ. Central neurocircuitry associated with emesis. Am J Med. 2001;111(Suppl 8A):106S-112S.

63. Smout A, Fox M. Weak and absent peristalsis. Neurogastroenterol Motil. 2012;24(Suppl 1):40-47.

64. Andrews PL, Sanger GJ. Abdominal vagal afferent neurones: an important target for the treatment of gastrointestinal dysfunction. Curr Opin Pharmacol. 2002;2(6):650-656.

65. Clouse RE, Diamant NE. Motor function of the esophagus. In: Johnson LR, editor. Physiology of the Gastrointestinal Tract. 4th ed. Academic Press; 2006:913-927.

66. Di Stefano M, Papathanasopoulos A, Blondeau K, et al. Effect of buspirone, a 5-HT ${ }^{1 \mathrm{~A}}$ receptor agonist, on esophageal motility in healthy volunteers. Dis Esophagus. 2012;25(5):470-476.
67. Browning $\mathrm{KN}$. Role of central vagal $5-\mathrm{HT}_{3}$ receptors in gastrointestinal physiology and pathophysiology. Front Neurosci. 2015;9:413.

68. Marrosu F, Maleci A, Cocco E, Puligheddu M, Barberini L, Marrosu MG. Vagal nerve stimulation improves cerebellar tremor and dysphagia in multiple sclerosis. Mult Scler. 2007;13(9):1200-1202.

69. Kessing BF, SmoutAJ, Bennink RJ, Kraaijpoel N, Oors JM, Bredenoord AJ Prucalopride decreases esophageal acid exposure and accelerates gastric emptying in healthy subjects. Neurogastroenterol Motil. 2014; 26(8):1079-1086.

70. Fox M, Menne D, Stutz B, Fried M, Schwizer W. The effects of tegaserod on oesophageal function and bolus transport in healthy volunteers: studies using concurrent high-resolution manometry and videofluoroscopy. Aliment Pharmacol Ther. 2006;24(7):1017-1027.

71. Li KL, Chen JH, Zhang Q, et al. Habitual rapid food intake and ineffective esophageal motility. World J Gastroenterol. 2013;19(14):2270-2277.

72. Lunding JA, Nordström LM, Haukelid AO, Gilja OH, Berstad A Hausken T. Vagal activation by sham feeding improves gastric motility in functional dyspepsia. Neurogastroenterol Motil. 2008;20(6): $618-624$.

73. Hasegawa Y, Sakagami J, Ono T, Hori K, Zhang M, Maeda Y. Circulatory response and autonomic nervous activity during gum chewing. Eur $J$ Oral Sci. 2009;117(4):470-473.

74. Kimmel JN, Carlson DA, Hinchcliff M, et al. The association between systemic sclerosis disease manifestations and esophageal high-resolution manometry parameters. Neurogastroenterol Motil. Epub 2016 Feb 27.

75. Singh J, Cohen S, Mehendiratta V, et al. Effects of scleroderma antibodies and pooled human immunoglobulin on anal sphincter and colonic smooth muscle function. Gastroenterology. 2012;143(5): 1308-1318.

76. Cunningham KM, Horowitz M, Riddell PS, et al. Relations among autonomic nerve dysfunction, oesophageal motility, and gastric emptying in gastro-oesophageal reflux disease. Gut. 1991;32(12): 1436-1440.

77. Pandolfino JE, Kahrilas PJ, American GA. AGA technical review on the clinical use of esophageal manometry. Gastroenterology. 2005;128(1):209-224
Clinical and Experimental Gastroenterology

\section{Publish your work in this journal}

Clinical and Experimental Gastroenterology is an international, peerreviewed, open access, online journal publishing original research, reports, editorials, reviews and commentaries on all aspects of gastroenterology in the clinic and laboratory. This journal is included on PubMed. The manuscript management system is completely online
Dovepress

and includes a very quick and fair peer-review system, which is all easy to use. Visit http://www.dovepress.com/testimonials.php to read real quotes from published authors. 